\title{
Evaluation of Ventilators for Mouthpiece Ventilation in Neuromuscular Disease
}

\author{
Sonia Khirani PhD, Adriana Ramirez MSc, Vincent Delord MSN, Karl Leroux Eng, \\ Frédéric Lofaso MD PhD, Solène Hautot Eng, Michel Toussaint PT PhD, \\ David Orlikowski MD PhD, Bruno Louis PhD, and Brigitte Fauroux MD PhD
}

\begin{abstract}
BACKGROUND: Daytime mouthpiece ventilation is a useful adjunct to nocturnal noninvasive ventilation (NIV) in patients with neuromuscular disease. The aims of the study were to analyze the practice of mouthpiece ventilation and to evaluate the performance of ventilators for mouthpiece ventilation. METHODS: Practice of mouthpiece ventilation was assessed by a questionnaire, and the performance of 6 home ventilators with mouthpiece ventilation was assessed in a bench test using 24 different conditions per ventilator: 3 mouthpieces, a child and an adult patient profile, and 4 ventilatory modes. RESULTS: Questionnaires were obtained from 30 subjects (mean age $33 \pm 11$ y) using NIV for $12 \pm 7 \mathrm{y}$. Fifteen subjects used NIV for $>20 \mathrm{~h} /$ day, and 11 were totally ventilatordependent. The subject-reported benefits of mouthpiece ventilation were a reduction in dyspnea (73\%) and fatigue (93\%) and an improvement in speech $(43 \%)$ and eating $(27 \%)$. The bench study showed that none of the ventilators, even those with mouthpiece ventilation software, were able to deliver mouthpiece ventilation without alarms and/or autotriggering in each condition. Alarms and/or ineffective triggering or autotriggering were observed in 135 of the 198 conditions. The occurrence of alarms was more common with a large mouthpiece without a filter compared to a small mouthpiece with a filter $(P<.001)$, but it was not related to the patient profile, the ventilatory mode, or the type of ventilator. CONCLUSIONS: Subjects are satisfied with mouthpiece ventilation. Alarms are common with home ventilators, although less common in those with mouthpiece ventilation software. Improvements in home ventilators are needed to facilitate the expansion of mouthpiece ventilation. Key words: daytime mouthpiece ventilation; neuromuscular disease; home ventilators; bench; questionnaire. [Respir Care 2014;59(9):1329-1337. (c) 2014 Daedalus Enterprises]
\end{abstract}

\section{Introduction}

Numerous neuromuscular diseases are characterized by an inevitable decline in respiratory muscle performance,

Dr Khirani, Ms Ramirez, and Dr Fauroux are affiliated with the Pediatric Pulmonary Department, Assistance Publique-Hôpitaux de Paris, Hôpital Armand Trousseau, Paris, France. Ms Ramirez and Mr Leroux are affiliated with the Association d'Entraide des Polios et Handicapés Assistance, Suresnes, France. Mr Delord is affiliated with ASV Santé, Gennevilliers, France. Dr Lofaso is affiliated with Physiologie-Explorations Fonctionnelles, Services de Réanimation Médicale, and the Centre d'Innovations Technologiques Unité Mixte de Recherche 805, Hôpital Raymond Poincaré, Assistance Publique-Hôpitaux de Paris, Garches, France, and EA 4497, Université de Versailles, Saint-Quentin-en-Yvelines, France. Drs Lofaso, Louis, and Fauroux are affiliated with the Institut National de la Santé et de la Recherche Médicale U955, Université Paris Est, Faculté de Médecine, Centre National de la Recherche resulting in progressive nighttime and ultimately daytime respiratory failure. Noninvasive ventilation (NIV) is a rec-

Scientifique ERL 7240, Créteil, France. Ms Hautot is affiliated with IBIOM, Ingénierie pour le Biomédical, Faculté des Sciences et Techniques, Université de Rouen, Saint-Étienne du Rouvray, France. Dr Toussaint is affiliated with the Neuromuscular Excellence Center, VUB-Inkendaal, and the Center for Home Mechanical Ventilation, Z.H. Inkendaal Rehabilitation Hospital, Brussels, Belgium. Dr Orlikowski is affiliated with the Service de Réanimation Médicale, Hôpital Raymond Poincaré, Assistance Publique-Hôpitaux de Paris, Garches, France, and the Université de Versailles, Saint-Quentin-en-Yvelines, France. Dr Khirani is also affiliated with S2A Santé, Ivry sur Seine, France. Dr Fauroux is also affiliated with Université Pierre et Marie Curie-Paris 6, Paris, France.

Dr Fauroux is supported by the Association Française contre les Myopathies, Vaincre la Mucoviscidose, Assistance Publique-Hôpitaux de Paris, Institut National de la Santé et de la Recherche Médicale, Université 


\section{Mouthpiece Ventilation in Neuromuscular Disease}

ognized and validated first-line treatment for respiratory failure in these subjects. ${ }^{1,2}$ Indeed, NIV normalizes nocturnal gas exchange and initially also daytime gas exchange. ${ }^{3}$ However, as respiratory muscle weakness progresses, daytime ventilatory failure may occur, which requires the extension of NIV during the day.

\section{See the Related Editorial on Page 1460}

Daytime ventilation can be performed with the interface used at night or a mouthpiece as sip ventilation. ${ }^{4}$ Mouthpiece ventilation has been reported to reduce the risk of respiratory infection due to tracheostomy and to improve cough, speech, dyspnea, survival, and patient quality of life. ${ }^{5-8}$ Mouthpiece ventilation is not widely used due to a lack of knowledge or information but also to inadequate equipment. Few supports are commercially available. Different mouthpieces can be used, with the choice being determined by the ability of the patient to seal his lips around the mouthpiece during a sip but also by the resistance of the mouthpiece. ${ }^{9}$ Indeed, most of the current home ventilators have not been specifically designed for mouthpiece ventilation. Home ventilators have low-pressure alarms that sound when circuit pressure drops, indicating tube disconnection. Thus, open-circuit ventilation cannot be performed because of low-pressure alarms. However, open-circuit mouthpiece ventilation can be realized when sufficient peak inspiratory flow is used to create enough back pressure $\left(2-3 \mathrm{~cm} \mathrm{H}_{2} \mathrm{O}\right.$ ) due to mouthpiece resistance. ${ }^{9}$ When the ventilator backup rate in the assist/control mode is sufficient to prevent apnea alarms, the ventilator circuit may normally remain open for extended periods without low-pressure or apnea alarms. The patient may be able to receive a ventilator-assisted breath as often as needed by making a sip effort through the mouthpiece. Only one bench study analyzed the ability of home ventilators to

\footnotetext{
Pierre et Marie Curie-Paris 6, Association d'Entraide des Polios et Handicapés Assistance, ASV Santé, IP Santé Domicile, and S2A Santé. ResMed (Saint-Priest, France) participated in the design of the questionnaire and the collection of the questionnaire data but had no role in data analysis, interpretation of the results, writing the manuscript, or the decision to submit the paper for publication. The Centre d'Innovations Technologiques received to pay for statistical analysis of the questionnaire results. The authors have disclosed no other conflicts of interest.

Supplementary material related to this paper is available at http:// www.rcjournal.com.

Correspondence: Brigitte Fauroux MD PhD, Pediatric Noninvasive Ventilation and Sleep Unit, Assistance Publique-Hôpitaux de Paris, Hôpital Necker, 149 rue de Sèvres, F-75015 Paris, France. E-mail: brigitte. fauroux@nck.aphp.fr.
}

DOI: $10.4187 /$ respcare.03031

\section{QUICK LOOK}

\section{Current knowledge}

Daytime mouthpiece ventilation is a useful adjunct to nocturnal noninvasive ventilation in subjects with neuromuscular disease. Mouthpiece ventilation improves patient tolerance and reduces fatigue.

\section{What this paper contributes to our knowledge}

Patients prescribed daytime mouthpiece ventilation are satisfied with this therapy. Home mechanical ventilators designed for invasive ventilation have frequent alarms during mouthpiece ventilation. Home ventilators with software to promote mouthpiece ventilation have fewer alarms and improve patient satisfaction.

provide mouthpiece ventilation. ${ }^{9}$ This study showed that 6 of 8 home ventilators supported mouthpiece ventilation, but all of the ventilators that supported mouthpiece ventilation maintained a functional low-pressure alarm in the event of a circuit disconnect when set at the respective manufacturer's minimum alarm pressure.

The first aim of our study was thus to analyze the practice of mouthpiece ventilation. The second aim was to evaluate the performance of 6 home ventilators for mouthpiece ventilation.

\section{Methods}

\section{Clinical Survey}

The survey was part of a large French and Belgium survey on long-term mechanical ventilation in neuromuscular subjects. The general objectives of the survey were (1) to evaluate the subjects' knowledge about and comfort with their long-term mechanical ventilation, (2) to compare subjects' and prescribers' opinions and expectations regarding long-term mechanical ventilation, and (3) to compare the equipment used by the subjects with the prescribers' current mechanical ventilation prescriptions. The detailed description and results of the survey have been published recently. ${ }^{10}$

In brief, data were collected via questionnaires specifically developed for the study. The patient questionnaires were completed by health care professionals between September 2010 and July 2011. A health care professional explained all of the definitions such as synchronization, effectiveness, comfort of ventilation, and others in order to improve the understanding of the questions. The objective was to include at least 200 subjects with an equal distribution between subjects treated with NIV during the night 


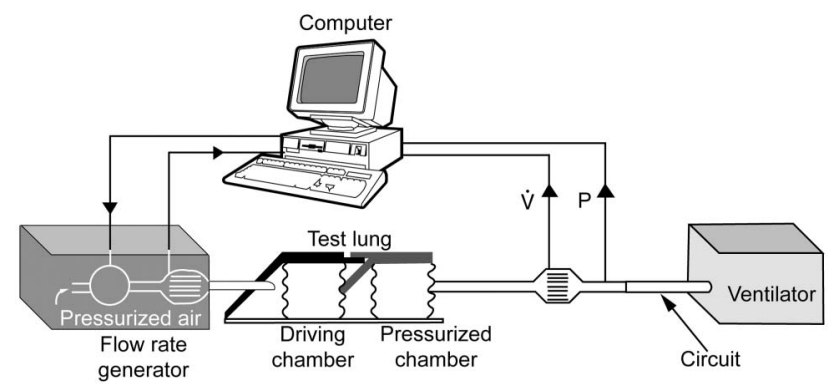

Fig. 1. Bench model used for the study. $\dot{V}=$ air flow; $P=$ airway pressure.

only, subjects treated with NIV during both the night and day, and subjects treated with invasive mechanical ventilation via a tracheostomy. Subjects were recruited in reference medical centers for neuromuscular diseases in Belgium (Inkendaal) and France (Lille, Grenoble, Marseille, Nice, Paris, and Garches) and in residential facilities for neuromuscular subjects in France (Évry, Montpellier, and Angers). The criteria for patient inclusion were (1) diagnosis of a neuromuscular disorder, (2) mechanical ventilation for at least 1 year, and (3) the willingness and availability to participate in the study (an interview of $90 \mathrm{~min}$ ). The scientific committee decided not to include subjects with amyotrophic lateral sclerosis due to the rapid progression of this disease. For the study, only subjects using mouthpiece ventilation were analyzed.

The study was approved by the Commission Nationale de l'Informatique et des Libertés in agreement with French regulation.

\section{Bench Study}

The aim of the bench study was to evaluate if the ventilator was able to deliver mouthpiece ventilation without alarms and/or autotriggering or ineffective triggering. The 6 most recent life-support ventilators available in France for home ventilation were tested as described. ${ }^{11}$ Each ventilator was connected via its standard circuit to a chamber Michigan test lung (MII VentAid TTL, Michigan Instruments, Grand Rapids, Michigan) (Fig. 1). As the PB560 (LX010101/AL020002, Covidien, Mansfield, Massachusetts), Trilogy 100 (13.0, Philips Respironics, Murrysville, Pennsylvania), and VS III (1.12, ResMed, Saint-Priest, France) ventilators have specific mouthpiece ventilation software, all three were also tested with this configuration.

For each ventilator, a pediatric and an adult profile of recorded subjects were tested. The pediatric profile was issued from the record of a 4-year-old patient with spinal muscular atrophy, having a spontaneous tidal volume $\left(\mathrm{V}_{\mathrm{T}}\right)$ of $10 \mathrm{~mL} / \mathrm{kg}$, a compliance of $0.038 \mathrm{~L} / \mathrm{cm} \mathrm{H}_{2} \mathrm{O}$, and an airway resistance of $52 \mathrm{~cm} \mathrm{H}_{2} \mathrm{O} /$ L.s. We used a Pneuflo airway resistor Rp50 (Flow Michigan Instruments, Grand
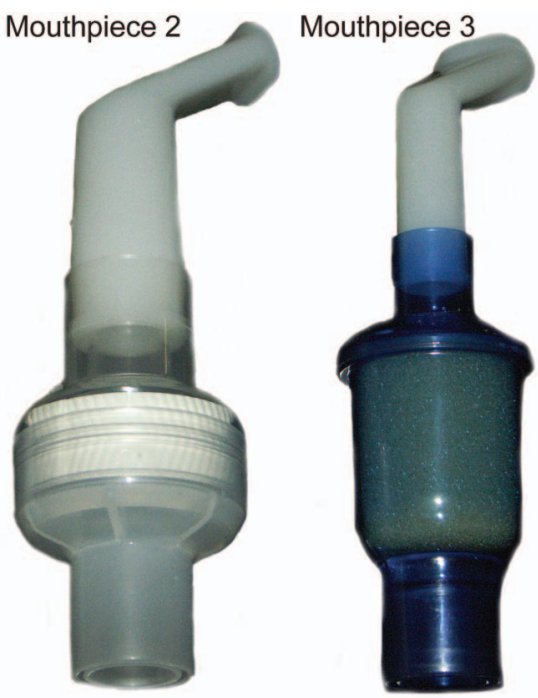

Fig. 2. Mouthpieces and filters used for the bench study. \#1: Large rigid plastic mouthpiece (22-mm angled, Philips Respironics). \#2: Large rigid plastic mouthpiece (22-mm angled, Philips Respironics) with a filter (Dar heat-and-moisture exchanger, Covidien). \#3: Small rigid plastic mouthpiece (15-mm angled, Philips Respironics) with a filter (Hygroflux 1, Vygon, Ecouen, France).

Rapids, Michigan), which is characterized by a nonlinear parabolic pressure flow relationship, to create a similar airway resistance. $\mathrm{Rp} 50$ introduces a $6.8 \mathrm{~cm} \mathrm{H}_{2} \mathrm{O}$ pressure drop for a $0.25 \mathrm{~L} / \mathrm{s}$ flow and a $27.2 \mathrm{~cm} \mathrm{H}_{2} \mathrm{O}$ pressure drop for a $0.5 \mathrm{~L} / \mathrm{s}$ flow. This pediatric profile was tested with 2 volume control settings with $\mathrm{V}_{\mathrm{T}} 250 \mathrm{~mL}(12.5 \mathrm{~mL} / \mathrm{kg})$ and $500 \mathrm{~mL}(25 \mathrm{~mL} / \mathrm{kg})$, pressure support mode with an inspiratory pressure of $15 \mathrm{~cm} \mathrm{H}_{2} \mathrm{O}$, and pressure control mode with an inspiratory pressure of $15 \mathrm{~cm} \mathrm{H}_{2} \mathrm{O}$. The adult profile was derived from the record of a 17-year-old patient with Duchenne muscular dystrophy, having a spontaneous $\mathrm{V}_{\mathrm{T}}$ of $5 \mathrm{~mL} / \mathrm{kg}$, a compliance of $0.024 \mathrm{~L} / \mathrm{cm} \mathrm{H} \mathrm{H}_{2} \mathrm{O}$, and an airway resistance of $17 \mathrm{~cm} \mathrm{H}_{2} \mathrm{O} /$ L.s. We used a Pneuflo airway resistor Rp20, which introduced a $4.4 \mathrm{~cm} \mathrm{H}_{2} \mathrm{O}$ pressure drop for a $0.5 \mathrm{~L} / \mathrm{s}$ flow and a $17.6 \mathrm{~cm} \mathrm{H} \mathrm{H}_{2} \mathrm{O}$ pressure drop for a $1.0 \mathrm{~L} / \mathrm{s}$ flow. This adult profile was also tested with 2 volume control settings with $\mathrm{V}_{\mathrm{T}} 500 \mathrm{~mL}(12.5 \mathrm{~mL} / \mathrm{kg})$ and $1000 \mathrm{~mL}(25 \mathrm{~mL} / \mathrm{kg})$, a pressure support mode with an inspiratory pressure of $20 \mathrm{~cm} \mathrm{H}_{2} \mathrm{O}$, and pressure control with an inspiratory pressure of $20 \mathrm{~cm} \mathrm{H}_{2} \mathrm{O}$. The backup rate of each ventilator was set at the lowest value, and all of the ventilator alarms were set to maximum. The inspiratory triggers were set at the most sensitive value without autotriggering.

Each ventilator was tested with 3 mouthpieces, a large rigid plastic mouthpiece and a small mouthpiece with or without a filter (Fig. 2). As expected, the resistance was the highest in the small mouthpiece with a filter and the lowest in the large mouthpiece without a filter. (See the supplementary materials at http://www.rcjournal.com.) 


\section{Mouthpiece Ventilation in Neuromuscular Disease}

For each condition, the following parameters were computed from each pressure and flow trace: trigger time delay (time delay from the onset of inspiratory effort to the moment during which the airway pressure exceeds the expiratory pressure $[\Delta \mathrm{T}]$ ) and trigger pressure (maximum negative pressure deflection from baseline $[\Delta \mathrm{P}]){ }^{11-13} \mathrm{Sig}-$ nals were digitized at $200 \mathrm{~Hz}$ using an analog/digital system (MP100, Biopac Systems, Goleta, California) and recorded on a microcomputer for further analysis.

Concerning the quality of the inspiratory trigger, we used the following criteria for the pediatric profiles only. The inspiratory trigger was considered to be appropriate if $\Delta \mathrm{T} \leq 100 \mathrm{~ms}$ and $\Delta \mathrm{P} \leq 1 \mathrm{~cm} \mathrm{H}_{2} \mathrm{O}$, acceptable if $\Delta \mathrm{T} \leq 150 \mathrm{~ms}$ and $\Delta \mathrm{P} \leq 1.5 \mathrm{~cm} \mathrm{H}_{2} \mathrm{O}$, and inappropriate if $\Delta \mathrm{T} \geq 150 \mathrm{~ms}$ or $\Delta \mathrm{P}>1.5 \mathrm{~cm} \mathrm{H}_{2} \mathrm{O}$ or in case of the non-detection of the inspiratory effort by the ventilator or autotriggering. ${ }^{11}$

\section{Statistical Analysis}

Data are given as mean \pm SD for quantitative data. Qualitative conditions were compared with a chi-square test. A $P$ value $<.05$ was considered to be significant.

\section{Results}

\section{Survey}

Completed questionnaires were collected from 209 neuromuscular subjects. Only 11 subjects refused to answer the questionnaire. Thirty of the 209 (14\%) subjects used mouthpiece ventilation. Their mean age was $33 \pm 11$ years, and they had been using NIV for $12 \pm 7$ years (Table 1 ). Fifteen subjects used NIV for $>20 \mathrm{~h} /$ day, and 11 were totally ventilator-dependent. The majority of the subjects used the same ventilator during the night and day (18/25, 72\%). The Eole (Saime, Savigny-le-Temple, France) and Legendair (Covidien) ventilators were used by $77 \%$ of the subjects, mostly $(75 \%)$ in the assist/control mode. Twelve subjects used a double-limb ventilator circuit, 11 subjects used a single-limb circuit with an expiratory valve, and 7 subjects used a single-limb circuit with an intentional leak. The ease of use (or convenience) of the mouthpiece circuit was rated by the subjects as $7 \pm 3$ on a visual analog scale (0: bad; 10: very good), with 6 subjects having no opinion. The ease of use of the mouthpiece by the subjects was also rated as $7 \pm 3$, with again 6 subjects having no opinion. As expected, the subjects considered it very important $(9 \pm 2$ on a visual analog scale) to have the mouthpiece as close as possible to their mouths. Seven subjects used mouthpiece ventilation exclusively for prolonged continuous periods of time, 4 subjects used it only for short intermittent breaths, and 8 subjects used it for both short and prolonged continuous periods of time, with no response available for 11 subjects. When the subjects were asked about the fre-
Table 1. Characteristics of Subjects and Mouthpiece Ventilation

\begin{tabular}{|c|c|}
\hline Characteristics & Value \\
\hline Women/men, $n$ & $8 / 22$ \\
\hline Age, mean $\pm \mathrm{SD}, \mathrm{y}$ (range) & $33 \pm 11(13-64)$ \\
\hline \multicolumn{2}{|l|}{ Neuromuscular disease, $n$} \\
\hline Duchenne muscular dystrophy & 14 \\
\hline Fascioscapular muscular dystrophy & 3 \\
\hline Congenital myopathy & 3 \\
\hline Becker dystrophy & 1 \\
\hline Metabolic myopathy & 1 \\
\hline Spinal muscular atrophy & 7 \\
\hline Other neuromuscular disease & 1 \\
\hline Subjects using a wheelchair, $n$ & 29 \\
\hline Subjects with a ventilator on wheelchair, $n$ & 21 \\
\hline Duration of NIV, mean $\pm \mathrm{SD}, \mathrm{y}$ (range) & $12 \pm 7(2-28)$ \\
\hline Daily duration of NIV, mean $\pm \mathrm{SD}, \mathrm{h}$ (range) & $19 \pm 6(8-24)$ \\
\hline Subjects using NIV $>20 \mathrm{~h} /$ day, $n$ & 15 \\
\hline Subjects using NIV $24 \mathrm{~h} /$ day, $n$ & 11 \\
\hline \multicolumn{2}{|l|}{ Subjects using ventilator equipment, $n$} \\
\hline Same ventilator night and day & 18 \\
\hline Different ventilator night and day & 7 \\
\hline Not specified & 5 \\
\hline \multicolumn{2}{|l|}{$\begin{array}{l}\text { Subjects using ventilators with mouthpiece } \\
\text { ventilation, } n\end{array}$} \\
\hline Eole & 13 \\
\hline Legendair & 10 \\
\hline PB560 & 2 \\
\hline VS Ultra* & 2 \\
\hline Harmony $\dagger$ & 1 \\
\hline Not specified & 2 \\
\hline \multicolumn{2}{|l|}{$\begin{array}{l}\text { Subjects using ventilatory mode during } \\
\text { mouthpiece ventilation, } n\end{array}$} \\
\hline Assist mode & 3 \\
\hline Control mode & 4 \\
\hline Assist/control mode & 21 \\
\hline Not specified & 2 \\
\hline \multicolumn{2}{|l|}{ Fixation of mouthpiece, $n$} \\
\hline On the patient & 10 \\
\hline On the wheelchair & 6 \\
\hline On a stand & 6 \\
\hline Not specified & 8 \\
\hline Use of triggering during mouthpiece ventilation, $n$ & 11 \\
\hline $\begin{array}{l}\text { Comfort with mouthpiece ventilation triggering/ } \\
10, \text { mean } \pm \mathrm{SD} \text { (range) }\end{array}$ & $7.4 \pm 3.7(1-10)$ \\
\hline $\begin{array}{l}* \text { ResMed } \\
\dagger \text { Philips Respironics } \\
\text { NIV = noninvasive ventilation }\end{array}$ & \\
\hline
\end{tabular}

quency, they expired into the ventilatory circuit, the mean response was $4 \pm 3$, on a visual analog scale (0: never; 10 : always), with no response from 2 subjects. Eleven subjects used the inspiratory trigger during mouthpiece ventilation with a visual analog scale comfort reported at a mean value of $7 \pm 4$ (Table 1). When the subjects were asked if they were interested in increasing the delivered $\mathrm{V}_{\mathrm{T}}$ on 


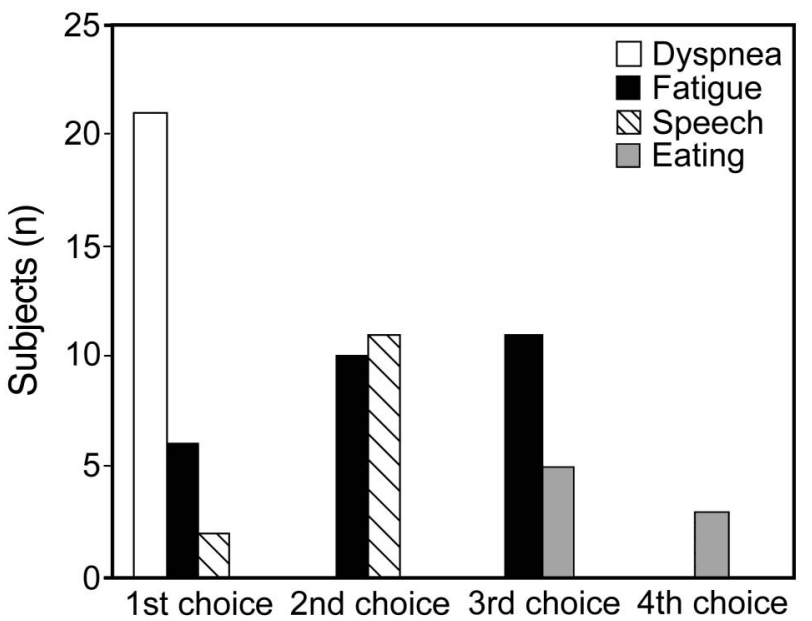

Fig. 3. Subject-reported benefits of mouthpiece ventilation ranked by priority.

demand (eg, for airway clearance), 17 subjects were interested, with a mean visual analog scale interest reported at $6 \pm 3$.

Figure 3 shows the subjects' self-estimated benefits from mouthpiece ventilation. The reduction in dyspnea was rated as the most important benefit by 22 subjects (73\% of subjects), followed by reduction in fatigue (93\%). Facilitation of speech (43\% of subjects) and eating (27\%) were rated as the third and fourth most important benefits, respectively. Other reported advantages were better vision (23 subjects), reduction in skin injury (19 subjects), facilitation of swallowing (11 subjects), and a decrease in aerophagia (7 subjects). One subject reported that his tracheostomy could be avoided due to mouthpiece ventilation.

\section{Bench Study}

The qualitative and partial quantitative performance data on the 3 ventilators with no mouthpiece ventilation software and the 3 ventilators with mouthpiece ventilation software are given in Tables 2 and 3, respectively. (See the supplementary materials at http://www.rcjournal.com.) The main results are that none of the 6 ventilators tested was able to deliver mouthpiece ventilation without alarms and/or ineffective triggering or autotriggering in the different conditions (135 of 198 conditions). For both the pediatric and adult profiles, alarms and/or ineffective triggering or autotriggering was less common with the small mouthpiece and a filter compared to the large mouthpiece without a filter $(P<.001$ for both profiles, $P=.008$ for the pediatric profile, and $P=.039$ for the adult profile). The occurrence of alarms and/or ineffective or autotriggering was not related to the subject profile $(P=.99)$, the ventilatory mode $(P=.69)$, or the type of ventilator $(P=.95)$. However, alarms occurred less often with the VS III ven- tilator compared to the other devices. Of note, even if the Trilogy mouthpiece ventilator is not designed to trigger like a classical ventilator, alarms were observed in only 2 of the 18 conditions when a whisper valve was added.

Of the 20 pediatric conditions that were not associated with an alarm and/or ineffective triggering or autotriggering, the trigger was appropriate in only 2 conditions (see Tables 2 and 3). The best triggers were observed with the large or small mouthpiece and a filter. The pediatric triggers were too long with the Elisée ventilator (ResMed) and were associated with autotriggering and/or ineffective triggering for the PB560, Trilogy 100, and Vivo 50 (Breas Medical, Saint-Priest, France) ventilators.

\section{Discussion}

This study shows that mouthpiece ventilation is used in highly ventilator-dependent subjects who claim an important subjective clinical benefit from this type of ventilation with regard to a decrease in dyspnea and fatigue and an improvement in speech and eating. These data contrast with the high prevalence of alarms and autotriggering or ineffective triggering observed with 6 home life-support ventilators when used with this type of ventilation.

\section{Survey}

The results of our survey confirm that mouthpiece ventilation is effective in postponing invasive ventilation by tracheostomy. Indeed, the majority of the subjects were highly ventilator-dependent, with approximately one third of the subjects being totally ventilator-dependent and half of the subjects requiring ventilatory assistance for $>20 \mathrm{~h} /$ day. It is probable that at least some of these subjects would have been tracheotomized in the absence of mouthpiece ventilation. ${ }^{6,14}$ This medical benefit is associated with a subjective benefit reported by the subjects. Indeed, all the subjects reported that mouthpiece ventilation was associated with important improvements in dyspnea and fatigue and facilitation of speech and eating, as reported by others..$^{5,8,14}$

Different ventilator circuits were used by the subjects. The use of a double-limb circuit is expected to be associated with fewer alarms if the patient exhales into the expiratory line due to the maintenance of a sufficient minimum pressure to avoid low-pressure alarms. However, our survey revealed that 11 subjects used a single-limb ventilator circuit with an expiratory valve, and 7 subjects used a single-limb circuit with an intentional leak. Regarding exhalation, the subjects' responses were highly variable, with some subjects always exhaling and others never exhaling into the expiratory limb in a double circuit.

The lack of use of the trigger is explained by extreme respiratory muscle weakness. Indeed, subjects with ad- 


\section{Mouthpiece Ventilation in Neuromuscular Disease}

Table 2. Qualitative and Partial Quantitative Functioning of the 3 Ventilators Without Mouthpiece Ventilation Software With 3 Different Mouthpieces and 2 Patient Profiles (Child and Adult) in the Bench Test

\begin{tabular}{|c|c|c|c|c|c|}
\hline \multirow{2}{*}{ Ventilator } & \multirow[b]{2}{*}{ Profile } & \multirow{2}{*}{ Ventilatory settings } & \multicolumn{3}{|c|}{ Alarm response to setting } \\
\hline & & & $\begin{array}{l}\text { Large mouthpiece } \\
\text { without a filter }\end{array}$ & $\begin{array}{l}\text { Large mouthpiece } \\
\text { with a filter }\end{array}$ & $\begin{array}{l}\text { Small mouthpiece } \\
\text { with a filter }\end{array}$ \\
\hline \multirow[t]{8}{*}{ Elisée 150} & \multirow[t]{4}{*}{ Child } & VC-CMV, $250 \mathrm{~mL}$ & LP alarm + open circuit & LP alarm + open circuit & LP alarm + open circuit \\
\hline & & VC-CMV, $500 \mathrm{~mL}$ & LP alarm + open circuit & $\begin{array}{l}\Delta \mathrm{T} 0.53 \mathrm{~s}, \Delta \mathrm{P} \\
\quad-0.67 \mathrm{~cm} \mathrm{H}_{2} \mathrm{O}\end{array}$ & $\Delta \mathrm{T} 0.57 \mathrm{~s}, \Delta \mathrm{P}-0.60 \mathrm{~cm} \mathrm{H}_{2} \mathrm{O}$ \\
\hline & & $\begin{array}{l}\text { VC-IMV with PS, } \\
15 \mathrm{~cm} \mathrm{H}_{2} \mathrm{O}\end{array}$ & LP alarm + open circuit & LP alarm + open circuit & $\Delta \mathrm{T} 0.55 \mathrm{~s}, \Delta \mathrm{P}-0.91 \mathrm{~cm} \mathrm{H}_{2} \mathrm{O}$ \\
\hline & & $\begin{array}{l}\text { PS with security } V_{T} \text {, } \\
15 \mathrm{~cm} \mathrm{H}_{2} \mathrm{O}\end{array}$ & LP alarm + open circuit & LP alarm + open circuit & $\Delta \mathrm{T} 0.34 \mathrm{~s}, \Delta \mathrm{P}-0.88 \mathrm{~cm} \mathrm{H}_{2} \mathrm{O}$ \\
\hline & \multirow[t]{4}{*}{ Adult } & VC-CMV, $500 \mathrm{~mL}$ & LP alarm + open circuit & $\begin{array}{l}\Delta \mathrm{T} 0.21 \mathrm{~s}, \Delta \mathrm{P} \\
\quad-1.33 \mathrm{~cm} \mathrm{H}_{2} \mathrm{O}\end{array}$ & $\Delta \mathrm{T} 0.20 \mathrm{~s}, \Delta \mathrm{P}-1.13 \mathrm{~cm} \mathrm{H}_{2} \mathrm{O}$ \\
\hline & & VC-CMV, $1000 \mathrm{~mL}$ & HP alarm & HP alarm & HP alarm \\
\hline & & $\begin{array}{l}\text { VC-IMV with PS, } \\
20 \mathrm{~cm} \mathrm{H}_{2} \mathrm{O}\end{array}$ & LP alarm + open circuit & $\begin{array}{l}\Delta \mathrm{T} 0.19 \mathrm{~s}, \Delta \mathrm{P} \\
\quad-1.44 \mathrm{~cm} \mathrm{H}_{2} \mathrm{O}\end{array}$ & $\Delta \mathrm{T} 0.18 \mathrm{~s}, \Delta \mathrm{P}-1.31 \mathrm{~cm} \mathrm{H}_{2} \mathrm{O}$ \\
\hline & & $\begin{array}{l}\text { PS with security } V_{T} \text {, } \\
20 \mathrm{~cm} \mathrm{H}_{2} \mathrm{O}\end{array}$ & LP alarm + open circuit & $\begin{array}{l}\Delta \mathrm{T} 0.19 \mathrm{~s}, \Delta \mathrm{P} \\
\quad-1.47 \mathrm{~cm} \mathrm{H}_{2} \mathrm{O}\end{array}$ & $\Delta \mathrm{T} 0.18 \mathrm{~s}, \Delta \mathrm{P}-1.49 \mathrm{~cm} \mathrm{H}_{2} \mathrm{O}$ \\
\hline \multirow[t]{8}{*}{ Monnal T50* } & \multirow[t]{4}{*}{ Child } & VC-CMV, $250 \mathrm{~mL}$ & Patient disconnect & Patient disconnect & Patient disconnect \\
\hline & & VC-CMV, $500 \mathrm{~mL}$ & Patient disconnect & Patient disconnect & Patient disconnect \\
\hline & & $\begin{array}{l}\text { PC-CMV } \\
\quad 15 \mathrm{~cm} \mathrm{H}_{2} \mathrm{O}\end{array}$ & $\begin{array}{l}\text { Patient disconnect }+ \text { high } \\
\text { MVI }\end{array}$ & Patient disconnect & $\Delta \mathrm{T} 0.09 \mathrm{~s}, \Delta \mathrm{P}-0.23 \mathrm{~cm} \mathrm{H}_{2} \mathrm{O} \dagger$ \\
\hline & & PS, $15 \mathrm{~cm} \mathrm{H}_{2} \mathrm{O}$ & Patient disconnect & Patient disconnect & $\Delta \mathrm{T} 0.08 \mathrm{~s}, \Delta \mathrm{P}-0.23 \mathrm{~cm} \mathrm{H}_{2} \mathrm{O}^{\dagger}$ \\
\hline & \multirow[t]{4}{*}{ Adult } & VC-CMV, $500 \mathrm{~mL}$ & Patient disconnect & Patient disconnect & Patient disconnect \\
\hline & & VC-CMV, $1000 \mathrm{~mL}$ & HP alarm/patient disconnect & $\begin{array}{l}\text { HP alarm/patient } \\
\text { disconnect }\end{array}$ & HP alarm/patient disconnect \\
\hline & & $\begin{array}{l}\text { PC-CMV, } \\
20 \mathrm{~cm} \mathrm{H}_{2} \mathrm{O}\end{array}$ & High inspiratory $\mathrm{V}_{\mathrm{T}}$ alarm & $\begin{array}{l}\text { Patient disconnect }+ \\
\text { high MVI }\end{array}$ & Patient disconnect + high MVI \\
\hline & & PS, $20 \mathrm{~cm} \mathrm{H}_{2} \mathrm{O}$ & Patient disconnect & Patient disconnect & $\Delta \mathrm{T} 0.09 \mathrm{~s}, \Delta \mathrm{P}-0.33 \mathrm{~cm} \mathrm{H}_{2} \mathrm{O}^{\dagger}$ \\
\hline \multirow[t]{8}{*}{ Vivo 50} & \multirow[t]{4}{*}{ Child } & VC-CMV, $250 \mathrm{~mL}$ & LP alarm & LP alarm & LP alarm \\
\hline & & VC-CMV, $500 \mathrm{~mL}$ & LP alarm & $\begin{array}{l}\Delta \mathrm{T} 0.11 \mathrm{~s}, \Delta \mathrm{P} \\
\quad 0.52 \mathrm{~cm} \mathrm{H} \mathrm{H}_{2} \mathrm{O}+\mathrm{IT}\end{array}$ & $\Delta \mathrm{T} 0.11 \mathrm{~s}, \Delta \mathrm{P} 0.52 \mathrm{~cm} \mathrm{H}_{2} \mathrm{O}+\mathrm{IT}$ \\
\hline & & $\begin{array}{l}\text { PC-CMV, } \\
\qquad 15 \mathrm{~cm} \mathrm{H}_{2} \mathrm{O}\end{array}$ & $\begin{array}{l}\Delta \mathrm{T} 0.18 \mathrm{~s}, \Delta \mathrm{P} \\
\quad-0.22 \mathrm{~cm} \mathrm{H}_{2} \mathrm{O}+\mathrm{IT}\end{array}$ & $\mathrm{AT}+\mathrm{IT}$ & $\begin{array}{l}\Delta \mathrm{T} 0.45 \mathrm{~s}, \Delta \mathrm{P}-0.36 \mathrm{~cm} \mathrm{H}_{2} \mathrm{O}+\mathrm{AT} \\
\quad+\mathrm{IT}\end{array}$ \\
\hline & & PS, $15 \mathrm{~cm} \mathrm{H}_{2} \mathrm{O}$ & $100 \%$ AT & $\mathrm{AT}+\mathrm{IT}$ & $\begin{array}{l}\Delta \mathrm{T} 0.38 \mathrm{~s}, \Delta \mathrm{P}-0.25 \mathrm{~cm} \mathrm{H}_{2} \mathrm{O}+\mathrm{AT} \\
\quad+\mathrm{IT}\end{array}$ \\
\hline & \multirow[t]{4}{*}{ Adult } & VC-CMV, $500 \mathrm{~mL}$ & LP alarm & $\begin{array}{l}\Delta \mathrm{T} 0.14 \mathrm{~s}, \Delta \mathrm{P} \\
\quad-0.34 \mathrm{~cm} \mathrm{H} \mathrm{H}_{2} \mathrm{O}\end{array}$ & $\Delta \mathrm{T} 0.28 \mathrm{~s}, \Delta \mathrm{P}-0.30 \mathrm{~cm} \mathrm{H}_{2} \mathrm{O}$ \\
\hline & & VC-CMV, $1000 \mathrm{~mL}$ & $\begin{array}{l}\Delta \mathrm{T} 0.14 \mathrm{~s}, \Delta \mathrm{P} \\
\quad-0.17 \mathrm{~cm} \mathrm{H}_{2} \mathrm{O}\end{array}$ & $\begin{array}{l}\Delta \mathrm{T} 0.17 \mathrm{~s}, \Delta \mathrm{P} \\
\quad-0.40 \mathrm{~cm} \mathrm{H}_{2} \mathrm{O}\end{array}$ & $\Delta \mathrm{T} 0.21 \mathrm{~s}, \Delta \mathrm{P}-0.44 \mathrm{~cm} \mathrm{H}_{2} \mathrm{O}$ \\
\hline & & $\begin{array}{l}\text { PC-CMV, } \\
\quad 20 \mathrm{~cm} \mathrm{H}_{2} \mathrm{O}\end{array}$ & $\begin{array}{l}\Delta \mathrm{T} 0.11 \mathrm{~s}, \Delta \mathrm{P} \\
\quad-0.37 \mathrm{~cm} \mathrm{H}_{2} \mathrm{O}\end{array}$ & $\begin{array}{l}\Delta \mathrm{T} 0.12 \mathrm{~s}, \Delta \mathrm{P} \\
-0.51 \mathrm{~cm} \mathrm{H}_{2} \mathrm{O}\end{array}$ & $\Delta \mathrm{T} 0.11 \mathrm{~s}, \Delta \mathrm{P}-0.44 \mathrm{~cm} \mathrm{H}_{2} \mathrm{O}$ \\
\hline & & PS, $20 \mathrm{~cm} \mathrm{H}_{2} \mathrm{O}$ & $\begin{array}{l}\Delta \mathrm{T} 0.14 \mathrm{~s}, \Delta \mathrm{P} \\
\quad-0.36 \mathrm{~cm} \mathrm{H}_{2} \mathrm{O}\end{array}$ & $\begin{array}{l}\Delta \mathrm{T} 0.15 \mathrm{~s}, \Delta \mathrm{P} \\
\quad-0.56 \mathrm{~cm} \mathrm{H}_{2} \mathrm{O}\end{array}$ & $\Delta \mathrm{T} 0.09 \mathrm{~s}, \Delta \mathrm{P}-0.43 \mathrm{~cm} \mathrm{H}_{2} \mathrm{O}^{\dagger}$ \\
\hline \multicolumn{6}{|c|}{ * Air Liquide Medical Systems, Antony, France } \\
\hline \multicolumn{6}{|c|}{$\dagger$ Trigger quoted as appropriate for pediatrics (see methods) } \\
\hline \multicolumn{6}{|c|}{ VC-IMV with PS = volume controlled intermittent mandatory ventilation (VC-IMV) with pressure support (PS) } \\
\hline \multirow{2}{*}{\multicolumn{6}{|c|}{ PC-CMV = pressure controlled continuous mandatory ventilation }} \\
\hline & & & & & \\
\hline \multicolumn{6}{|l|}{$\begin{array}{l}\mathrm{V}_{\mathrm{T}}=\text { tidal volume } \\
\mathrm{LP}=\text { low pressure }\end{array}$} \\
\hline \multicolumn{6}{|c|}{$\mathrm{HP}=$ high pressure } \\
\hline \multirow{2}{*}{\multicolumn{6}{|c|}{ MVI = inspiratory minute ventilation }} \\
\hline & & & & & \\
\hline \multicolumn{6}{|c|}{$\mathrm{IT}=$ ineffective triggering $>20 \%$ of respiratory cycles } \\
\hline \multirow{2}{*}{\multicolumn{6}{|c|}{$\Delta \mathrm{T}=$ trigger time delay }} \\
\hline & & & & & \\
\hline
\end{tabular}




\section{Mouthpiece Ventilation in Neuromuscular Disease}

Table 3. Qualitative and Partial Quantitative Functioning of the 3 Ventilators With Mouthpiece Ventilation Software With 3 Different Mouthpieces and 2 Patient Profiles (Child and Adult) in the Bench Test

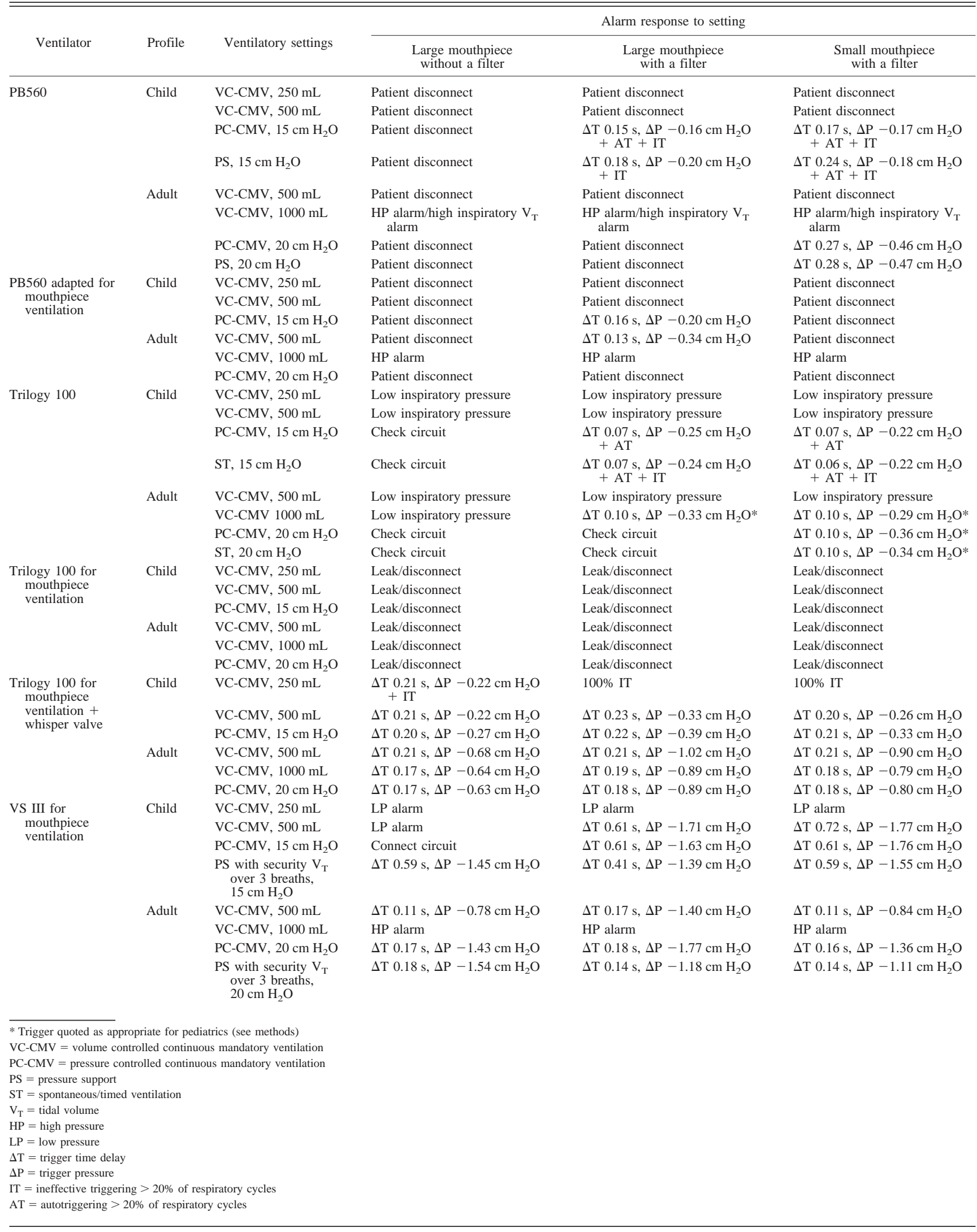




\section{Mouthpiece Ventilation in Neuromuscular Disease}

vanced neuromuscular disease are too weak to trigger the ventilator. Only half of the subjects used the trigger during mouthpiece ventilation with an acceptable level of comfort. This contrasts with the results of the bench study, which showed a poor quality of the inspiratory trigger in most of the conditions. As all of the subjects had very advanced respiratory muscle weakness, it is probable that they triggered the ventilator by means of a sip. Indeed, the negative pressure generated by a sip is much higher than that generated by a maximum static inspiratory pressure. ${ }^{15}$ However, after a sip maneuver, a patient with advanced neuromuscular disease will not be able to generate any inspiratory effort.

\section{Bench Study}

The bench study showed the high prevalence of alarms. Logically, open-circuit mouthpiece ventilation can be performed when sufficient peak inspiratory flow is used to create enough back pressure due to mouthpiece resistance to prevent low-pressure alarms in an open-circuit system. ${ }^{9}$ As expected, the small mouthpiece with a filter had the highest resistance, which explained the lower occurrence of low-pressure or disconnecting alarms.

We have no explanation for the differences observed between the 6 ventilators. Detailed information on the functioning and performance of home ventilators is generally not available. Indeed, the software with most ventilators is a classical example of a black box. Under United States and European administration regulations, marketing approval for a home ventilator device does not seem to require detailed descriptions of the current algorithms that determine the response of the ventilator to changes in respiratory system mechanics and leaks. In the absence of detailed information, it is thus impossible to explain the differences observed between the ventilators but also between the different ventilatory modes and settings for a particular ventilator. Within the same context, the algorithms that determine the low-pressure or disconnecting alarms vary according to each manufacturer, which precludes any comparison between different ventilators.

Interestingly, the Trilogy mouthpiece ventilator and whisper valve were associated with a reduction in alarms compared to the other configurations available with this ventilator. It should be emphasized that the "kiss" trigger available on the Trilogy mouthpiece ventilator is not comparable to a classical ventilator, as it is based on a flow signal technology that detects an alteration in the flow-by generated by the ventilator due to any reason, such as a partial obstruction via the mouth connection. In our bench test, in which we used a valve to stop the flow-by with variable velocity, preliminary results showed, first of all, that a complete interruption of the flow-by was not necessarily associated with a trigger detection but that a min- imum speed of variation of the flow-by (defined as the variation of flow over time) seemed necessary to the trigger detection and the delivery of $\mathrm{V}_{\mathrm{T}}$. After several tests, we observed a threshold of the flow-by of $0.13 \mathrm{~L} / \mathrm{s}^{2}$ necessary for the trigger detection (receiver operating characteristic curve: specificity $96 \%$, sensitivity $87 \%$, area under the curve $0.970, P<.05$ ).

Finally, it is important to emphasize the discrepancy between the alarm and inoperable settings observed in the bench test and the subjective satisfaction of the majority of the subjects with their actual mouthpiece ventilation. We do not have a clear explanation for this point, but it is possible that the subjects (and their caregivers) found some way to adapt with the excessive alarms or ventilator dysfunction.

In conclusion, this study shows that mouthpiece ventilation can be a viable treatment option for some subjects with neuromuscular disease and that it is used mainly by highly ventilator-dependent subjects who recognize an important subjective benefit of this type of ventilation. However, there are remarkable technical problems in setting up mouthpiece ventilation. A wider use will require that the equipment be made easier to set up and use properly. Indeed, together with the improvement of ventilator performance for mouthpiece ventilation, there is room for improvement in practical equipment such as mouthpieces and their fixation system and the ergonomy of the ventilators.

\section{REFERENCES}

1. Jeppesen J, Green A, Steffensen BF, Rahbek J. The Duchenne muscular dystrophy population in Denmark, 1977-2001: prevalence, incidence and survival in relation to the introduction of ventilator use. Neuromuscul Disord 2003;13(10):804-812.

2. Simonds AK, Muntoni F, Heather S, Fielding S. Impact of nasal ventilation on survival in hypercapnic Duchenne muscular dystrophy. Thorax 1998;53(11):949-952.

3. Mellies U, Ragette R, Dohna Schwake C, Boehm H, Voit T, Teschler H. Long-term noninvasive ventilation in children and adolescents with neuromuscular disorders. Eur Respir J 2003;22(4):631-636.

4. Affeldt JE. Round table conference on poliomyelitis equipment. White Plains, New York: National Foundation for Infantile Paralysis-March of Dimes; 1953.

5. Bach JR, Rajaraman R, Ballanger F, Tzeng AC, Ishikawa Y, Kulessa $R$, Bansal T. Neuromuscular ventilatory insufficiency: effect of home mechanical ventilator use vs. oxygen therapy on pneumonia and hospitalization rates. Am J Phys Med Rehabil 1998;77(1):8-19.

6. Bach JR, Saporito LR. Criteria for extubation and tracheostomy tube removal for patients with ventilatory failure. A different approach to weaning. Chest 1996;110(6):1566-1571.

7. Gomez-Merino E, Bach JR. Duchenne muscular dystrophy: prolongation of life by noninvasive ventilation and mechanically assisted coughing. Am J Phys Med Rehabil 2002;81(6):411-415.

8. Toussaint M, Steens M, Wasteels G, Soudon P. Diurnal ventilation via mouthpiece: survival in end-stage Duchenne patients. Eur Respir J 2006;28(3):549-555. 


\section{Mouthpiece Ventilation in Neuromuscular Disease}

9. Boitano LJ, Benditt JO. An evaluation of home volume ventilators that support open-circuit mouthpiece ventilation. Respir Care 2005; 50(11):1457-1461.

10. Lofaso F, Prigent H, Tiffreau V, Menoury N, Toussaint M, Monnier $\mathrm{AF}$, et al. Long-term mechanical ventilation equipment for neuromuscular patients: meeting the expectations of patients and prescribers. Respir Care 2014;59(1):97-106.

11. Fauroux B, Leroux K, Desmarais G, Isabey D, Clément A, Lofaso F, Louis B. Performance of ventilators for noninvasive positive-pressure ventilation in children. Eur Respir J 2008;31(6):1300-1307.

12. Lofaso F, Brochard L, Hang T, Lorino H, Harf A, Isabey D. Home versus intensive care pressure support devices. Experimental and clinical comparison. Am J Respir Crit Care Med 1996;153(5):15911599.

13. Fauroux B, Louis B, Hart N, Essouri S, Leroux K, Clément A, et al. The effect of backup rate during non-invasive ventilation in young patients with cystic fibrosis. Intensive Care Med 2004;30(4):673681.

14. Bach JR, Alba AS, Saporito LR. Intermittent positive pressure ventilation via the mouth as an alternative to tracheostomy for 257 ventilator users. Chest 1993;103(1):174-182.

15. Pellegrini N, Pelletier A, Orlikowski D, Lolierou C, Ruquet M, Raphaël JC, Lofaso F. Hand versus mouth for call-bell activation by DMD and Becker patients. Neuromuscul Disord 2007;17(7):532-536.

This article is approved for Continuing Respiratory Care Education credit. For information and to obtain your CRCE

(free to AARC members) visit www.rcjournal.com 